\title{
برنامج تلريبي للطالبة المعلمة قائم علي انتاج الوسائط التعليمية لتنمية جوانب النمو لطقل الروضة لئة
}

إعداد

د/ أحلام عبد العظيم حامد

م/ هند حمد العتيبي

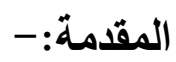

تعد مرحلة الطفولة من أهم المراحل في تكوين شخصية الفرد وتشكيل وعيه وتوجيه سلوكه، وتمنل هذه المرحلة النواة الأساسية لنمو الشخصية بما تحمله من مفاهيم وقيم وسلوكيات.

ولأهمية مرحلة الطفولة يجب الاهتمام بمن يساهم في تشكيل شخصية الطفل ووعيه في هذه المرحلة ، وتعتبر معلمة الروضة من الثخصيات الرئيسية التى يتعامل معها الطفل ويتأثز بها وتؤثز في تشكيل وعيه وتوجيه سلوكه.

ولذلك يجب أن تكون المعلمة ماهرة ومعدة إعداداً أكاديمياً وتربوياً، ويقصد بذلك أن يتم

إعدادها أثناء دارستها - أي وهى طالبة معلمة - إعداداً جيداً، بحيث تكون ملمة بالأساليب والوسائط الحديثة التي تؤثز في تتمية جوانب النمو المختلفة للطفل، وتتمي شخصيته ومن هذه الوسائط القصة التكنولوجية والأفلام التعليمية والبرمجيات ، وعلى الجانب الأخر يجب أن تكون الطالبة المعلمة قادرة على توظيف الوسائط التعليمية لإمداد الطفل بالمعلومات والقيم والسلوكيات بأسلوب شيق وجذاب، ( ياسمين أحمد ، $(r \cdot 1), 4 r q$

لقد أصبح التطور التكنولوجي الآن سمة من سمات العصر الذى نعيش فيه ، ولا بسنطع أي مجتمع من المجتمعات أن يتخلف عن ملاحقة هذا التطور التكنولوجي في جميع ميادين الحياة الاجتماعية والعلمية والثقافية والاقتصادية والصناعية وجميع الميادين الأخرى.

وبما أن التربية هي جزء من هذا المجتمع فعليها أن تلاحق هذا التطور التكنولوجي وتعكسه فيما تقدمه من برامج تعليمية لأطفال الغد ، بأساليب تكنولوجية جديدة تتفق وتساير هذه الثورة التكنولوجية والمعلوماتية الحادثة الآن. 


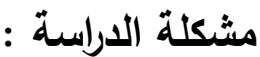

لاحظت الباحثتان قصور معرفي لاى الطالبة المعلمة من خلال التنريس لهن بالوسائط المتعددة وطرق توظيفها التوظيف الأمتل لتحقيق أهدافها التربوية في الروضة ،وخاصة أن الطالبات المعلمات عينة الدراسة يذهبون للروضات الخارجية للمشاهدات الميدانية والتعامل مع الأطفال وذللك ضمن خطتهن الدراسية ولتتمية جوانب النمو المختلفة التي يمر بها الطفل في هذه المرحلة

مما يؤثز سلبا على الطفل الذى سوف تتعامل معه فيما بعد حيث ان الطالبة المعلمة اليوم هي معلمة الغد ولذا يجب أن يكون لديها معرفة جيدة بجوانب النمو وخصائصه المختلفة. وقد لاحظت الباحثتان في حدود علمها ندرة الدارسات التي تتاولت التدريب علي اعداد وتتفيذ الوسائط التعليمية للطالبات المعلمات وتحديداً بتوظيف الطالبة المعلمة للقصة والبرمجية والكتيب المصور لتنمية جوانب النمو المختلفة لطفل الروضة مما يعطى أهمية لهذه الدراسة. وتتحدد مشكلة الدراسة في التساؤل الرئيسي التالي :ما مدى فاعلية البرنامج التدريبي للطالبة المعلمة لإكسابها مهارة إنتاج و توظيف الوسائط التعليمية لتتمية جوانب النمو لطفل الروضة؟ ويتفرع من هذا التساؤل الرئيسي عدد من التساؤلات الفرعية الآتية

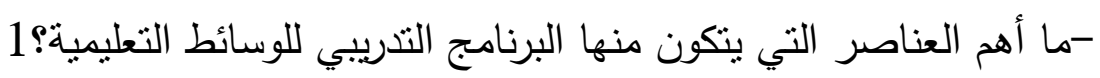
- - -ما هي المهارة اللازم اكسابها للطالبة المعلمة لتتمية جوانب النمو المختلفة لطفل الروضة؟ كما توصلت الباحثتان بعد الاطلاع على الأدبيات والدراسات السابقة أن هنالك ندرة في الدراسات التي تتاولت

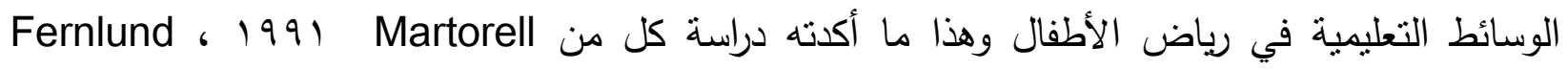
199 (اوان استخدام الوسائط المتعددة يجعل من المعلم موجه ومرشد ومصمم مبدع في الفصول الدراسية

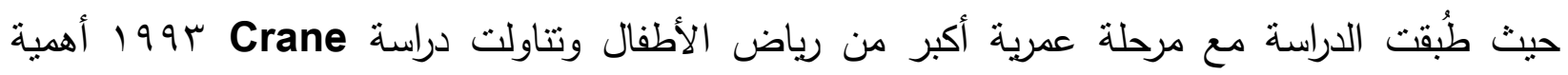
استخدام تكنولوجيا التعليم في التدريس ، وليس الاعتماد على المواد والوسائل التقليدية مقارنة بالوسائط

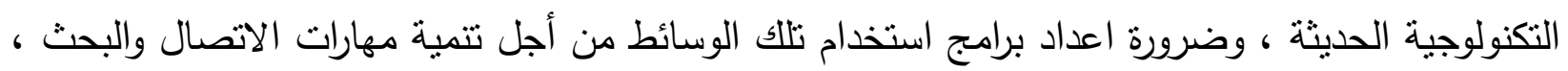
مع اعداد مشروعات عديدة للاستخدام في الفصل من خلال الوسائط المتعددة الحديثة للتدريس وتدريب المعلمين عليها قبل التطبيق. 
1- توعية الطالبة المعلمة بأهمية جوانب نمو طفل الروضة ץ-تدريب الطالبة المعلمة على مهارة انتاج الوسائط التعليمية لتتمية جوانب النمو للطفل.

\section{أهمية الدارسة :- (ارسة}

1-التأكيد على أهمية تدريب الطالبة المعلمة على الوسائط التعليمية المتتوعة تحديد دور الوسائط التعليمية في تتمية جوانب النمو لطفل الروضة2ب-توجيه أنظار المهتمين بمرحلة رياض الأطفال بأهمية دور الوسائط التعليمية وطرق نوظيفها من قبل فوريل

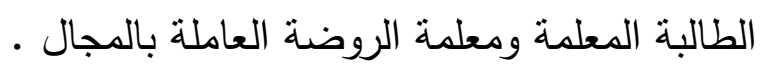

\section{منهج الاراسة :-}

اعتمدت الدراسة الحالية على المنهج التجريبي ذو المجموعة الواحدة ، حيث ثم استخدام القياسين القبلي والبعدي بهدف دراسة فعالية البرنامج التدريبي لإكساب الطالبة المعلمة دهارات انتاج و توظيف الوسائط

التعليمية لطفل الروضة عينة الدراسة :حيث تتمنل العينة فى •r طالبة معلمة، بالمستوي الثالث بقسم رياض الأطفال بكلية العلوم والدراسات الإنسانية بالجبيل

\section{حدود الدراسة :-}

سوف تقتصر حدود الدراسة المكانية على قسم رياض الأطفال كلية التربية-جامعة الإمام عبد الرحمن بن فيصل أماعن حدود الدراسة الزمنية فيتم تطبيق البرنامج لمدة شهرين بمعدل يومين في

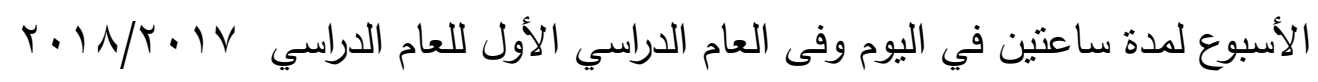
اما حدود الدراسة البشرية فتتمنل في الطالبات المعلمات بقسم رياض الأطفال - كلية العلوم والدراسات الإنسانية بالجبيل-جامعة الإمام عبد الرحمن بن فيصل 
1- اختبار تحصيلي للوسائط التعليمية للطالبة المعلمة

r- اختبار تحصيلي لجوانب النمو المختلفة لطفل الروضة

r- البرنامج التدريبي لإنتاج وتوظيف الوسائط التعليمية لتتمية جوانب النمو لطفل الروضة

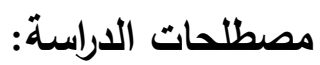

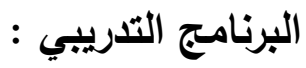

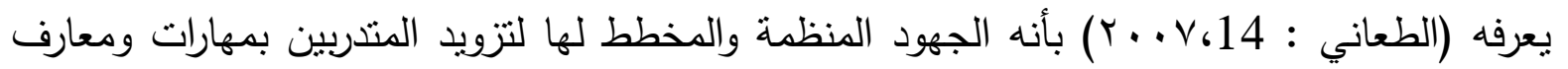
وخبرات متجددة تستهدف إحداث تغيرات إيجابية مستمرة في خبراتهم واتجاهاتهم وسلوكهم من أجل تطوير كفاية أدائهم

\section{الوسائط التعليمية : - ائ}

يعرفها (عرمان : Y...V.YTV) بأنها مزيج من الوسائط المختلفة الثابتة والمتحركة التي ترتبط بالحاسوب لنتير الى المزيج من الأصوات والصور في أجهزة مختلفة والمدمجة من خلال الحاسوب

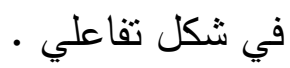

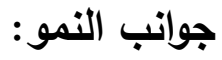

تعرفها ( وفاء:27;2013) تشكل جوانب النمو عند الانسان وحدة منماسكة ومتكاملة تعمل في انسجام وتوافق تام ، فهي ترتبط فيما بينها ارتباطا وظيفيا قويا ولللك يلاحظ انه اذا حدث اضطراب او نقص في أي مظهر منها أدى الى اضطراب في عملية النمو والاداء الوظيفي للشخصية بشكل عام وترتبط فيما بينها في مرحلة الطفولة 
الإطار النظري والدراسات السابقة :

أولاً: التدريب أثناء الخدمة:

تتغل قضية التدريب أثناء الخدمة للموارد البشرية مكان الصدارة عند بناء أب مؤسسة تعليمية منظورة،

لأن الفرد يمنل الوسيلة والهدف لإنجاز وأداء الأعمال والمهام المطلوبة، لذا فإن عملية التدريب

تهدف إلى صقل خبرات ومهارات ومعارف المنترب، بما يتلاءم مع تطور العصر، واحتياجات

الفرد وكفاياته الحالية والمستقلية، وكذا متطلبات العمل المستقلية وهو الهدف الأساسي للتنريب.

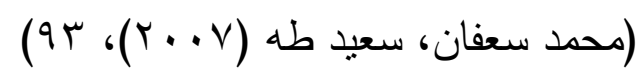

والفرد المستهدف بالتدريب أثناء العمل يتعلم بشكل أفضل عندما بسنطيع أن برى تطبيقاً فورياً للمهارات والمعرفة التي يتلقاها في برنامج التدريب، ونستطيع أن نؤكد ذلك عندما نجعل الأهداف التدريبية واقعية بالنسبة لمتطلبات العمل الفعلية، وحيث أن التدريب يحدث في بيئة العمل الواقعية، فمن بن السهل على المتدرب أن يرى قيمة الهدف وقيمة التدريب ذي الصلة بتحقيق هذا الهدف.

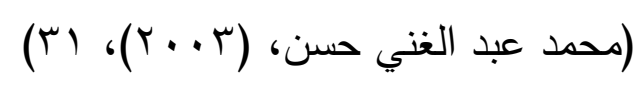

وترى الباحثتان أن التدريب يعتبر دعامة قوية من دعائم تتمية الطالبة المعلمة من جميع الجوانب، سواء

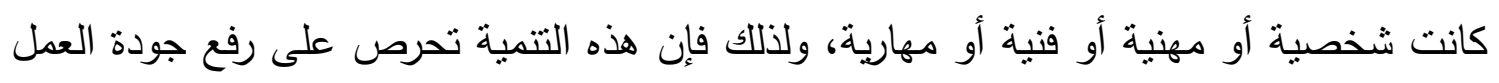
فيما بعد عن طريق تحسين الأساليب، وطرق العمل، والاستفادة من البيئة المحيطة، لنتمية الأطفال.

ولتوضيح أهية ندريب الطالبة المعلمة ينطلب ذلك التعرض لمفهوم التدريب وأهميته وأساليبه وأهدافه

$$
\text { وطرق تقويمه، وهذا ما ستقوم الباحثنان بتوضيحه. }
$$

\section{مفهوم التدريب أثناء الخدمة: In Service Training}

تعددت المفاهيم التي تتاولت التدريب أثناء الخدمة، فقد عرفها جودت عزت بأنه "برنامج مخطط يتكون من

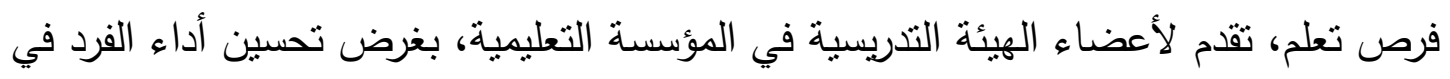

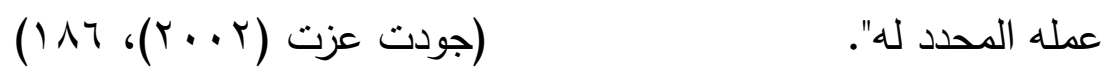


والتنريب كما عرّفه مايك ويلز "هو نقل معرفة ومهارات محددة وقابلة للقياس".

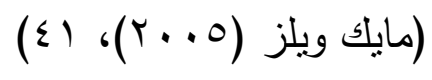

وقد عرف على راثد التدريب بأنه: "مجموعة من البرامج والدورات: الطويلة أو القصيرة أو الورش الدراسية، وغيرها من التنظيمات التي تتتهي بمنح شهادات أو مؤهلات دراسية، وتهدف إلى تقديم مجموعة من الخبراء: المعرفية والمهارية والوجدانية اللازمة للمتدرب لرفع مستواه التعليمي، والارتقاء بأدائه التربوي

والأكاديمي من الناحيتين: النظرية والعلمية".

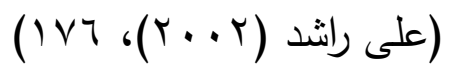

ويرى محمد سعفان وسعيد طه أنه يقصد به "كل البرامج المنظمة والمخطط لها، والتي تمكن المعلمين من الحصول على المزيد من الخبرات الثقافية والمهنية (والتخصصية) وكل ما من شأنه رفع مستوى

عملية التعليم وزيادة طاقات المعلمين الإنتاجية".

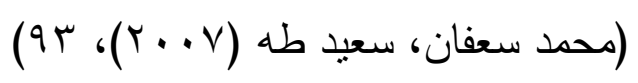

ويذكر حسن شحاته، زينب النجار "أن البرنامج التدريبي هو نوع من أنواع التنريب، يهدف إلى إعداد الأفراد وتدريبهم في مجال معين، وتطوير معارفهم ومهاراتهم واتجاهاتهم، بما يتفق مع الخبرات

التعليمية للمتدربين ونموهم وحاجاتهم لتتمية مهارة ما".

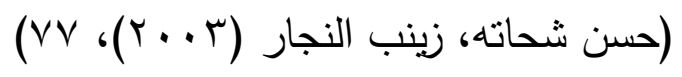

ويعرفه أحمد اللقاني وعلي الجمل: بأنه نموذج قائم على تحديد الكفايات اللازمة في تخصص ما، والذي ينبغي امتلاكها لممارسة هذا التخصص، ويتم وضح البرنامج في ضوئها مشتملاً على أهدافه، وأساليب تدريسه، والوسائل والأنشطة، وأساليب التقويم المناسبة له. (أحمد اللقاني، علي الجمل $(01,(1999)$

ويعرف محمد البدوي التدريب علي أنه "نشاط مخطط له يهدف لإحداث تغييرات إيجابية من المهارات

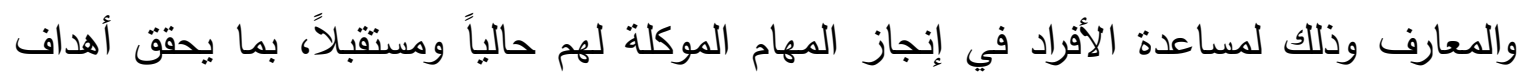

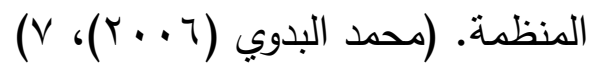

ويعرف التدريب أيضاً على أنه: "نشاط مستمر يركز على الفرد من أجل تحقيق تغيير هادف في 
معارفه ومهاراته، لمقابلة احتياجات محددة في الوضع الراهن والمستقبلي في ضوء عمل الفرد،

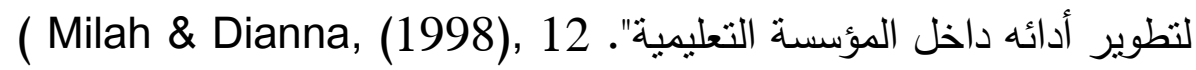
وفي ضوء ما سبق تعرف الباحثتان إجرائياً "البرنامج التدريبي" بأنه مجموعة من الإجراءات المنظمة والممارسات العملية التي تقوم بها الطالبة المعلمة تحت إثراف القائم على التدريب (الباحثنان) حيث ينظم له البيئة التدريبية المناسبة لتدريبه على مجموعة من المعلومات والمهارات والأدوار والمهام لتحقيق الأهداف المحددة لتعويد الأطفال على عادة القراءة مبكراً.

\section{ثانياً: أهمية التدريب أثناء الخدمة:}

تعددت المهام التي نحصل عليها من عملية التدريب، فللتدريب أهمية بالنسبة للفرد المتدرب، وبالنسبة للمؤسسة التي يعمل بها الفرد وسنوضحها فيما يلي: أ- أهمية التنريب بالنسبة للفرد:

1- يكسب التدريب المتدربين معارف ومهارات واتجاهات ذات علاقة مباشرة بالعمل ويطور أدائهم. r- يكسب الفرد ثقة بنفسه وقدرة على العمل دون الاعتماد على الآخرين، ويدعم احترامه لنفسه واحترام الآخرين له.

r- يكسب الفرد خبرات جديدة تؤهله إلى الارتقاء وتحمل مسئوليات أكبر ، قد تكون مسئوليات قيادية. ع-ينمي التدريب لدى الفرد المرونة والقدرة على التكيف في حياته العملية. 0- التدريب بوصفه جهاً منظماً مخططاً برتكز على تحسين الأداء الحالي والمستقبلي للأفراد (ساعد صباح والجماعات على حد سواء. $(1 \cdot 6(r \cdot 9)$ ب- أهمية التدريب بالنسبة للمؤسسة: 1- التدريب يؤدي إلى تحسين الأداء وبالتالي زيادة الجودة. r- التدريب يؤدي إلى تحسين سلوكيات الأفراد في المنظمة مما ينعكس على الأداء بالإيجاب. 
r- التدريب يؤدي إلى تحسين وضع المؤسسة التتافسي، وذلك من خلال تحقيق درجة الجودة المطلوبة. ع- - التدريب ينمي روح التعاون بين أفراد المنظمة من خلال التقائهم حول خبرات جديدة يكتسبونها معاً من خلال التدريب، وأيضاً فترة التقائهم خلال البرامج التدربية.

ه- التدريب يخلق نوعاً من الانتماء والولاء تجاه المنظمة مما يؤدي لبذل جهد أكثر من أجل المنشأة. 7- التكريب يخلق نوعاً من التوافق بين أهداف المنظمة وأهداف الأفراد.

- - - التدريب يكتتف وينمي المهارات في الأفراد، وبالتالي يقلل من الاعتماد على الخبرات الخارجية، مما

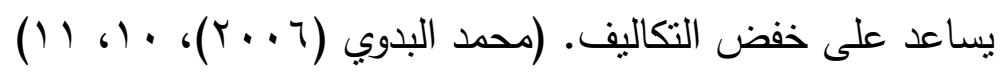

وتستخلص الباحثتان مهام التدريب في النقاط التالية:

- تعد عملية تدريب أمناء مكتبات الأطفال أثناء الخدمة ضرورة حتمية وأساسية في تتميتهم واطلاعهم على أنى الاتجاهات والأساليب المستحدثة، سواء فيما يتعلق بالمعارف العلمية أو بتطوير طرق تقديم الخدمة المكتبية ومن ثم الارتقاء بأداء أمناء المكنبة نحو الأفضل دائماً. - تعتبر عملية التثريب أثناء الخدمة مرحلة مكملة لعملية الإعداد قبل الخدمة كما أنها تقرض على أمناء مكتبات الأطفال الاطلاع على كل ما هو جديد عالمياً أو محلياً. - يجعل أمناء المكتبة متجددين ومتطورين في مهنتهم ومنسجمين مع مجموعة المتغيرات التي تحيط بهم في المجتمع من تكنولوجيا المعلومات ،أو تغير في طبيعة الأطفال أنفسهم التي تختلف من يوم إلي آخر . - و هذا يستدعي من أمناء مكتبة الطفل الإلمام بكل ما بطرأ في عالم الأطفال والخدمة المكتبية الموجهة إليهه.

- يعتبر التدريب أثناء الخدمة ضرورة حتمية في مهنة أمناء المكتبات لرفع كفاءة الفرد، وتجديد ثقافته ومهاراته ومعلوماته وقدراته، بما يمكنه من التكيف مع عمله من ناحية ومواجهة المشكلات من ناحية 
ثالثاً: أهداف التدريب أثناء الخدمة: - م

يمكن تقسيم الأهداف التدريبية إلى أهداف عامة وأهداف خاصة ويمكن تحديد الأهداف العامة للتدريب

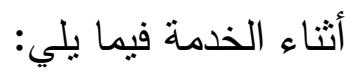

الأهداف العامة:

تنمية الاتجاهات السليمة للقرد نحو تقدير قيمة عمله التريوي، والإداري، وأهميته، والآثار أ الاجتماعية المتصلة به والمترتبة عليه.

تنمية مفهوم التربية المستمرة، والإسهام في الحلقات الاراسية، والدراسات الميدانية وغيرها. ب-

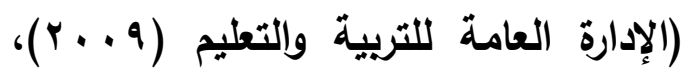

- والأهداف الخاصة للتدريب أثناء الخدمة يمكن تحديدها فيما يلي: 1- سد الاحتياجات التدريبية للعاملين في مجالات التعليم والقيادات التربوية. r- تفادي الأخطاء في أعمالهم والتقليل منها ما أمكن، والحفاظ على الوقت والجهد والمال. r- ـيادة قدرة المتدربين على التفكير المبدع، بما يمكنه من التكيف مع أعمالهم من ناحية ومواجهة مشكلاتهم المستقبلية، والتغلب عليها من ناحية أخرى. ع - تعريف المتدربين بكيفية القيام بواجبات رسالتهم ووظائفها.

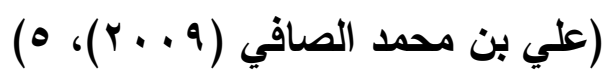
رابعاً: أهداف تدريب الطالبة المعلمة: أكدت دراسة خالد حسين إبراهيم على ذلك من خلال:

التعرف على الطرق التقليدية المستحثثة في تقدير الاحتياجات التدريبية للطالبة المعلمة 
التعرف على الطرق الحديثة في تقدير الاحتياجات التدريبية.

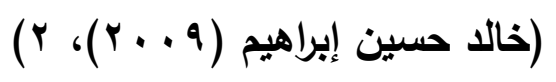

الارتقاء المهني في مجال الوظيفة والتكيف مع متطلبات الأدوار المهنية المنتظرة.

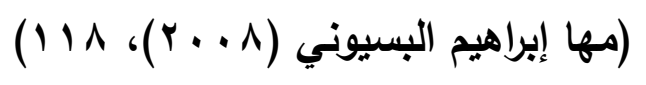

وترى الباحثتان أن أهداف البرنامج التدريبي شيء نسبي، بمعنى أنه يختلف من برنامج إلى آخر، ويتنوع باختلاف أنماط برامج التدريب ومستوى المتدربين، ونوعيتهم المستهدفة، ومكان التدريب،

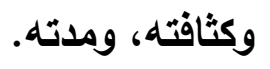

خامساً: خطوات البرنامج التدريبي:

وتتضمن خطوات تصميم البرامج التدريبية ما يأتي:

$$
\text { - - - تحديد هدف البرنامج. }
$$

$$
\begin{aligned}
& \text { r- تحديد عدد الدارسين والثروط التي يجب أن تتوافر فيهم. } \\
& \text { r- نظام التدريب أثناء تتفيذ البرنامج التدريبي. }
\end{aligned}
$$

ع- تحديد معايير أو مسنويات الأداء الذي يجب أن يصل إليها المتدرب.

0- تحديد الفترة الزمنية المخصصة للبرنامج التدريبي مع توزيع الوقت الكلي للبرنامج على الموضوعات المختلفة.

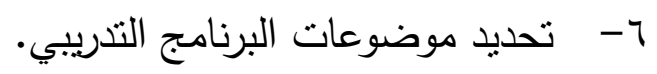

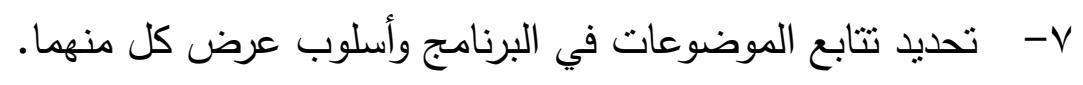

ᄉ- - تحديد النماذج العملية والتطبيقات المناسبة لكل موضوع، وتحديد وضعها في البرنامج. 
9- تحديد دور الدارسين في البرنامج وأنواع الواجبات المفروضة عليهم من قيام بحوث ودراسات شاملة، فردية وجماعية.

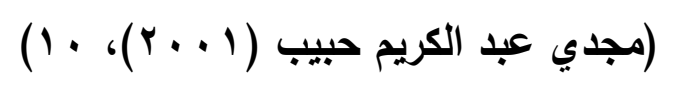

ولقد راعت الباحثتان نلك الخطوات عند إعدادها البرنامج التدريبي، حيث حددث هدف البرنامج وماهي الدهارات والمعارف التي يجب أن تتقنها الطالبة المعلمة حتى نساعدهم على تقديم القراءة القداء الارشادية، وحدت عدد المندربات ونظام التدريب وكيفية النقويم.

سادساً: مبادئ التدريب

ولكي يحقى البرنامج التريبي أهدافه عليه أن يراعى اعتبارات ومبادئ ومنها: - - - أن يعتد بثكل مباثر على خبرة المجموعة المشاركة.

- - أن يقدم بيئة داعمة تتعامل فيها المشاركات باحترام، وتتاح لهن فرصة الإسهام وطرح الأفكار. - - أن يساعد أفراد المجموعة المشاركة في العمل طبقاً لمستويات أفهامهم المختلفة.

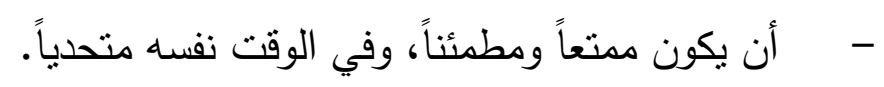
- - الإثنادة السريعة بالإنجازات، ومساعدة أفراد المجموعة المشاركة في تحديد الخطوة التالية التي سيتم اتخاذها فيما يتعلق بتعلميهم وأسلوب ممارستهم بأنفسهم.

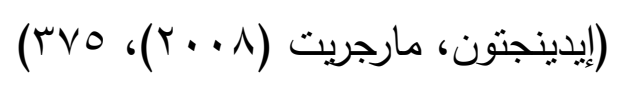

- - أن يكون هادفاً، وذلك حتى يكون معبراً عن الاحتياجات التدريبية ومدى الحاجة إليها. - - - الثمولية فيشمل كل الفئات والدرجات الوظيفية المختلفة. - - الواقعية وذلك بالالتزام باحتياجات المستهوفين في المضمون والمحتوى باستخدام الأسلوب المناسب معهم، والذي يجب أن يساير منطلباتهم، بحيث يؤدي إلى استكمال أي نقص لائهر. 
- - التأثثر وذلك يتطلب المواءمة بين اتجاهات المستهدفين، وما يقدم إليهم من معلومات، ومهارات،

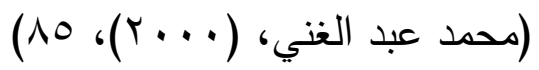
ومعارف جديدة.

سابعاً: الطرق والأساليب المستخدمة في التدريب:

يستلزم تنوع الاحتياجات التدريبية وتعدد مستويات البرنامج التدريبي، تنوع أساليب التدريب وتعدد أثنكالها، فما يصلح لإثباع بعض الاحتياجات التدريبية قد لا يصلح لإثباع احتياجات أخرى، ، من هنا يلزم تنويع أساليب التدريب في البرنامج بما يليق بكل فئة.. وقد تم التنويع في أساليب التدريب كالآتي:-

1- المحاضرات: وينبغي في إلقاء المحاضرات أن تقتصر على ما له صلة بالاحتياجات التدربيية للأفراد دون تكرار للمفاهيم والمبادئ التربوية العامة التي سبق له دراستها في كليات التربية أو البرامج التربوية.

r- حلقات المناقثة: وتتعقب بعض المحاضرات، وتستهدف تعديق المفاهيم التي تعرّض لها المحاضر . r- الندوات: وهذه تصلح لكافة مستويات التدريب شريطة كفاءة الاختبار للمشاركين فيها حسب كل مستوى من مسنويات التدريب.

ع- - الزيارات الميدانية: وفيها يقوم المتدربون بزيارة بعض الددارس التي طبقت بالفعل هذه المناهج، أو غير ذلك من مؤسسات ذات صلة بالمناهج والكتب المطورة. 0- كتابة أبحاث وتقارير : وهذه تعوّد المتدربين الاستقلال في تحصيل المعرفة والحرص على التعق فيها، ومن المهم هنا إعطاء البحوث والتقارير ما تستحقه من أهمية من الجهات الإثرافية، لا أن تظل هذه البحوث مجرد أداء شكلي.

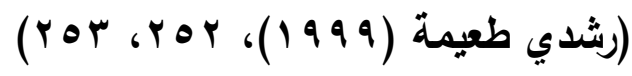

4- التعليم المصغر: هو أسلوب في التدريب يعتمد على تدريب مجموعة صغيرة من الأمينات على مهارة واحدة من المهارات المكتبية ويوجه التعليم المصغر إلى مجموعة من الأطفال، وبعد الانتهاء من التعليم لتلك المهارة تتاقش الأمينة وتزود بالتغذية الراجعة المناسبة. 
- - الورش التعليمية: لا تعتمد هذه الطريقة على إعطاء الدروس نظرياً فقط، وإنما على التدريب على

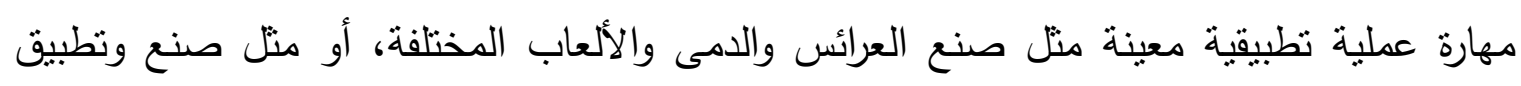
الوسائل التعليمية المختلفة، كتصميم اللوحة المغناطيسية أو اللوحة الوبرية أو الجيبة.

1- - لعب الأدوار : هو أسلوب من أساليب التعليم الحديثة وتتوقف فائدة أسلوب لعب الأدوار على نوعية

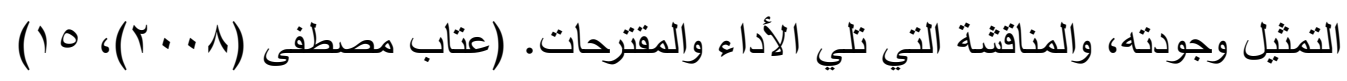

\section{ثامناً: تقويم البرنامج التدريبي:}

تعد خطوة تقويم البرنامج التدريبي بالغة الأهمية، ولكي نحدد معاً كيفية تقويم البرنامج التدريبي لابد أن

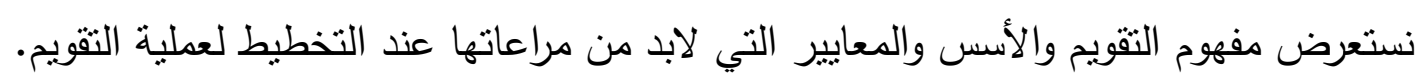

والتقويم هو : "عملية منهجية منظمة لجمع البيانات وتفسير الأدلة بما يؤدي إلى إصدار أحكام تتعلق

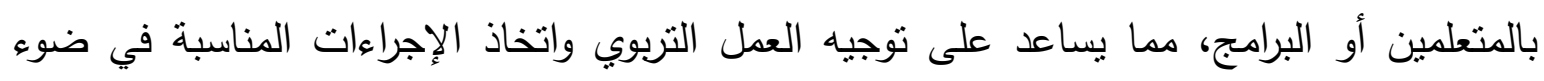

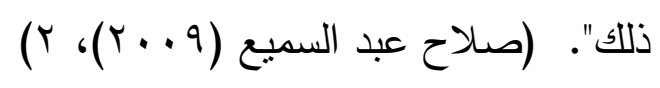

وهناك مجموعة من الأسس أو المعايير التي لابد من مراعاتها عند تخطبط عملية التقويم وتتفيذها: • أن يكون التقيم متكاملاً بمعنى أن يكون هنالك ترابط وتكامل وتتسيق بين الوسائل المستخدمة في التقويץ.

أن يراعي التقويم الاقتصاد في الوقت والجهد والمال.

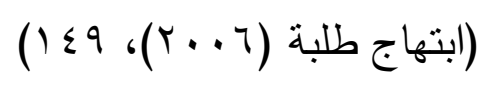

إن تقرير البرنامج التربوي والسير فيه يقتضي أن يكون هناك تقويم منتابع، ومستمر لما يتم إنجازه، بحيث إنه

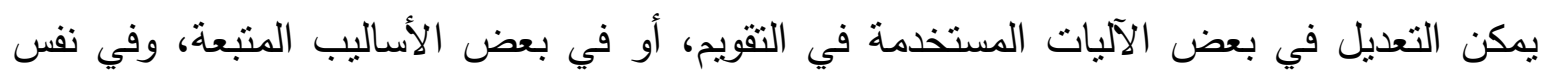

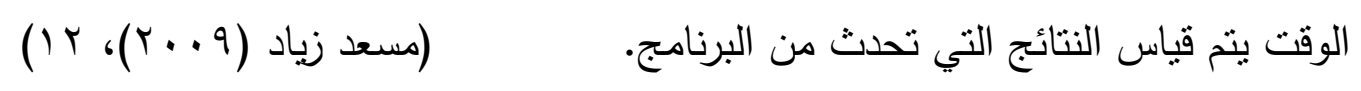

وترى الباحثنان أن عملية الثقويم ضرورية؛ لمعرفة وتحديد مدى تحقيق أهداف البرنامج التدريبي، وكذلك

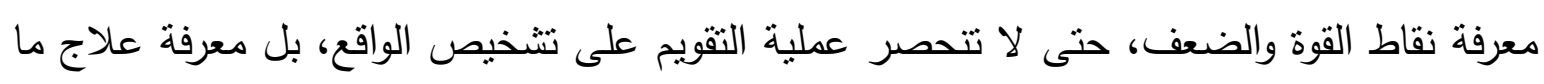


به من عيوب، حيث أنه يكفي في عملية التقويم معرفة أوجه القصور فقط، وإنما يجب العمل على تلافيها والتغلب عليها.

وعلى الجانب الأخر يجب أن تكون الطالبة المعلمة قادرة على نوظيف الوسائط التعليمية للإمداد الطفل بالمعلومات والقيم والسلوكيات بأسلوب شيق وجذاب.

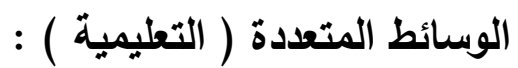

استخدم مصطلح الوسائط المتعددة منذ الستينيات ليصف الوسائط السمعية والبصرية التي تستعين بها المعلمة في عملية التدريس ، أي أن هذا المصطلح اقتصر في بداية ظهوره علي استخدام أكثر من وسيلة تعليمية في الموقف التعليمي الواحد ، ومع التطورات السريعة في مجال تكنولوجيا المعلومات منذ الثمانيات ، ارتبطت الوسائط المتعدة بتكنولوجيا الكمبيوتر وتكنولوجيا الاتصال عن بعد ، حيث أصبحت تتبر إلي صنف من برمجيات الكمبيوتر التي توفر المعلومات بأشكال مختلفة كالصوت والصورة والرسوم المتحركة ،

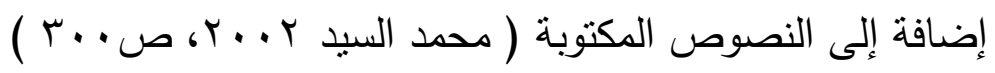
كما يمكن تعريف الوسائط المتعددة علي أنها استخدام الكمبيوتز في عروض و دمج النصوص، والرسومات، والصوت، والصورة بروابط وأدوات تسمح للمستخدم بالاستقاء، والتفاعل، والابتكار والاتصال.(عاطف

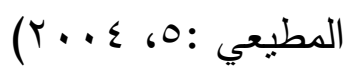
وتعرف الوسائط المتعددة بأنها فئة من نظم الاتصالات المتفاعلة التي يمكن إنتاجها وتقديمها بواسطة الكمبيوتر ، لتخزين و نقل واسترجاع المعلومات الموجودة في إطار شبكة من اللغة المكتوبة، والمسموعة، و الموسيقي، والرسومات الخطية، والصور الثابتة و الفيديو أو الصور المتحركة. كما تُعرف بأنها مصطلح يجمع عدداً من الوسائل كالنصوص و و الأصوات و الصور والرسوم و الفيديو.

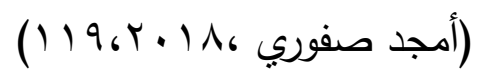
أنواع الوسائط المتعددة - - الوسائط المتعددة التقاعلية

تعد التفاعلية الميزة الأساسية للوسائط المتعددة حيث تعطي إمكانية التفاعل بينها وبين مستخدميها، فنحن نتفاعل مع أنثكال عديدة من الوسائط في حياتتا اليومية فمثلا عند تسجيل برنامج تليفزيوني يذاع في وقت

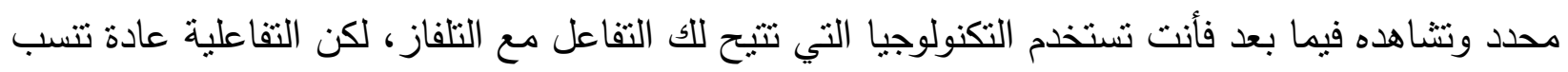
إلى الحاسوب لما له من مميزات في التخزين والعرض والبحث في كميات كبيرة من المعلومات. 


\section{ب - ب - ب الوسائط المتعددة الفائقة}

تعتبر الوسائط المتعددة الفائقة تطورا للوسائط المتعددة التفاعلية ، ولتوضيح مفهوم الوسائط المتعددة الفائقة نبدأ من مفهوم النص المترابط أو الفائق Hyper Text الذي يعد أساس التجول داخل شبكة المعلومات حيث تظهر في صفحات الإنترنت بعض الكلمات المميزة بلون مختلف عن لون النصوص بداخل الصفحة وعندما نشير إليها الفأرة يتحول شكل المؤشر إلى إثشارة يد وعند النقر عليها تنقلنا إلى موقع آخر في الثبكة كما يتضح مفهوم النص المترابط عند التجول داخل ملف المساعدة Help لغالبية البرامج (فاطمة

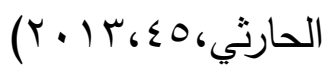

$$
\begin{aligned}
& \text { عناصر الوسائط المتعددة } \\
& \text { ا ـ النصوص المكتوبة } \\
& \text { r اللغة المنطوقة }
\end{aligned}
$$

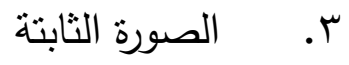

$$
\begin{aligned}
& \text { ع. ـالصور المتحركة } \\
& \text { ه. لقطات الفيديو } \\
& 7 \text { ـ الموسيقى والمؤثرات الصوتية }
\end{aligned}
$$

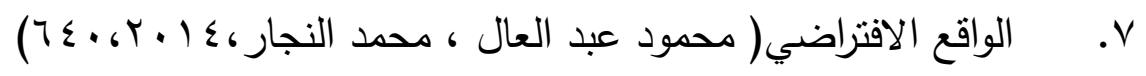

$$
\begin{aligned}
& \text { خصائص الوسائط المتعددة } \\
& \text { تتميز برامج الوسائط المتعددة بخواص عديدة منها مايلي: } \\
& \text { - - - - التكاملية }
\end{aligned}
$$

هو عبارة عن استخدام اكثر من وسيطين في الاطار الواحد بشكل تفاعلي وليس مستقل وحتى يتحقق التكامل بشكل جيد لابد من التقيد بعدة امور نذكر بعض منها: • عدم تكرار التعليق الصوتي لنفس محتوى النص المكتوب • عدم استخدام الصوت منفردا دون مصاحبة بعض المواد البصرية منل الرسوم المتحركة أو صدور

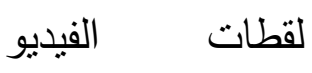
• لا يجوز أن يبدأ التعليق الصوتي قبل ظهور الصورة 
عدم الجمع بين وسيلتين بصريتين في نفس الإطار مثل عرض رسوم متحركة في نافذة ومقاطع من لقطات فيديو في نافذة مجاورة ربط الصورة والرسوم الثابتة التي تتحدث عن فكرة معينه أو مفهوم محدد بواسطة خلفية موسيقية واحدة غير منقطعة لان ذلك يوحي بالتتابع لموضوع واحد عدم استخدام المؤثرات الصوتية مع التعليق الصوتي فلابد أن تكون الموسيقى خافته مع وضوح

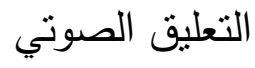

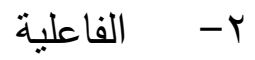

يشير التفاعل في مجال الوسائط المتعددة الى الفعل ورد الفعل بين المتابع وبين ما يعرضه الكومبيوتر ويتضمن ذللك قدرة المتعلم على التحكم فيما يعرض عليه وضبطه عند اختيار زمن العرض وتسلسله وتتابعه والخيارات المتاحة من حيث القدرة على اختيارها والتجوال فيما بينها. ب توفر عروض الوسائط المتعدة بيئة تعلم منتوعة يجد فيها كل شخص ما يناسبه و يتحقق ذلك عن طريق توفير مجموعة من البدائل والخيارات امام كل شخص.

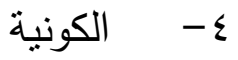

تتيح تكنولوجيا الوسائط المتعددة للمتعلم لكي يتعامل مع المعلومات على مستوى أكبر من مستوى المادة المتعلمة ويمكن للمتعلم الاتصال بشبكة الإنترنت للحصول على ما يحتاجه من معلومات في كافة مجالات

$$
\text { o- }
$$

والتزامن يعني مناسبة توقيتات تداخل العناصر المختلفة الموجودة في برنامج الوسائط المتعددة، فمراعاة التزامن يساعد على تحقيق خاصيتي التكامل و التفاعل. ب- الإتاحة

وتعني اتاحة عروض الوسائط المتعددة في الوقت الذي يحتاج المتعلم الى التعامل معها.

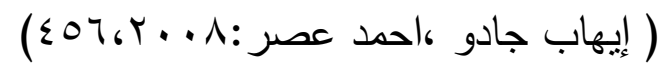
وتكمن أهمية استخدام الوسائط المتعددة في: 1-تشجيع الطلاب على الاتشترالك الفعال في العطلية التعليمية. 
r- تنتخدم على نطاق واسع في نظم التعليم البرامجي بوجه عام والتعليم الفردي بوجه خاص. r- تستخدم في مراكز التعلم للمواد المختلفة، ومراكز مصادر التعلم. ع - تستخدم لأغراض التدريب المختلفة للمعلمين وغيرهم.

0- تعمل على تتشيط الحواس المختلفة للمتعلم وتجعل التعلم أبقى أثرا. ד- تدريب الطلاب على التعامل مع الوسائط المتعددة خارج قاعة الدرس وفى عالمهم الحقيقي، وتقربهم من

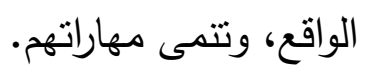
- V تتضمن مجموعة من أنظمة الوسائل التعليمية الحديثة والتي تثرى العملية التعليمية منل (الثرائح الفيلمية المصحوبة بالتسجيل الصوتي، أنظمة الصور المتعددة، برامج الحركة المختلفة، الفيديو ذات الفاعلية

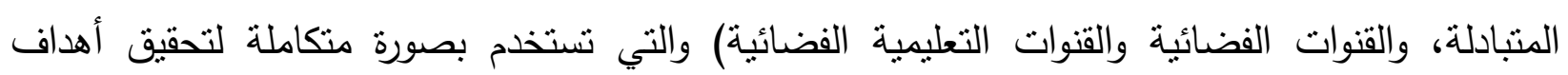

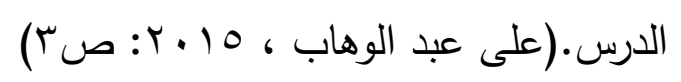

ولذلك يجب أن تكون المعلمة ماهرة ومعدة إعداداً أكاديمياً وتربوياً، ويقصد بذلك أن يتم إعدادها أثثاء دراستها أي وهى طالبة معلمة - إعداداً جيداً، بحيث تكون ملمة بجوانب النمو المختلفة في كل مرحة من مراحل حياة الطفل في الروضة وما يتعرض له من متغيرات فكرية وتربوية ونفسية تشكل شخصيته وسلوكه فيما بعد.

جوانب نمو الطقل :

وقبل التحدث عن خصائص نمو الطفل في هذه المرحلة لا بدّ أولاً من معرفة أنّ نمو الطفل ينقسم إلى ثلاثة

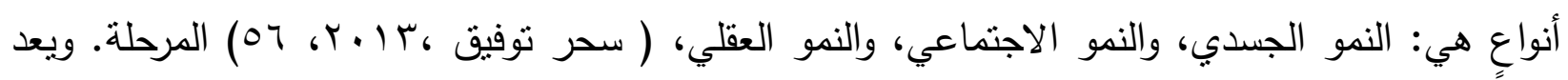
النمو العقلي من أبرز مظاهر وخصائص نمو هذه المرحلة التي ميزتها عن غيرها من مراحل نمو الأطفال ،

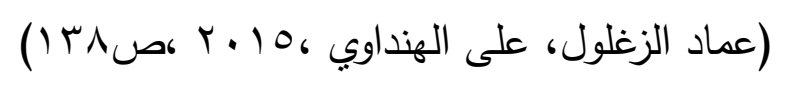

مرحلة رياض الأطفال (عقل ، محمود عطا ، ص ل (V ))، والتي ينبغي مراعاتها في العملية التربوية ؛ كون أي عملية تربوية لا تراعي ما تتطلبه هذه الخصائص من عوامل مساعدة على اكتساب القيم ، والمعلومات

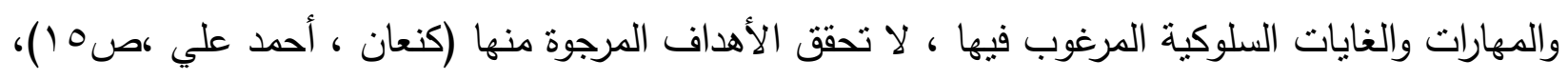
ومن خصائص نمو الأطفال ما يلي : خصائص النمو العقلي : يكون النمو العقلي عند الطفل في مرحلة رياض الأطفال نمواً سريعاً يغير في الطفل بشكلٍ كبيرٍ؛ وهناك الكثير من الخصائص التي تخص الناحية العقلية، منها: يتغير إدراك الطفل 
للأشياء من حوله من الإدرالك الكلي إلى الإدراك الجزئي. تتسع آفاقه وتكبر قدرته على التفكير، والتخيل،

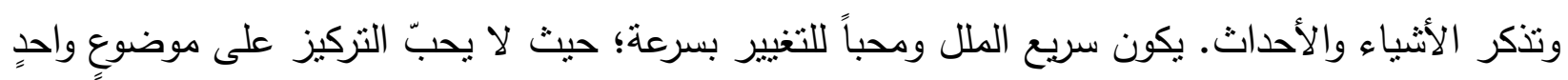
لفترٍ طويلةٍ. تزداد أسئلته بشكلٍ واضحِ ويزيد حب الاستطلاع والبحث عنده بشكلٍ ملحوظٍٍ. يعتمد بشكلٍ

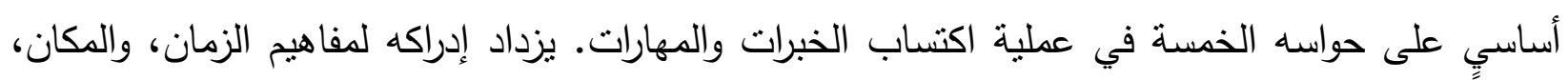
والكميات، ويتأخر إدراكه للأوزان قليلاً. خصائص النمو الاجتماعي: تزداد حدة انفعالاته وقوتها، ويكون كثير التقلب في ردود أفعاله وانفعالاته. يميز الأدوار التي يقوم بها أفراد الأسرة، بحيث يميز بين دور الأم، والأب، والأخ، والأخت، ويحاول تقليدهم في أغلب الأمور • يميز بين التصرفات المقبولة اجتماعياً وبين التصرفات غير المقبولة، ويكون هذا التمييز تدريجياً وليس مرةً واحدةً، وهذا ينوقف على الطريقة التي يعامله بها أهله. يحبّ السيطرة بشكلٍ أكبر من

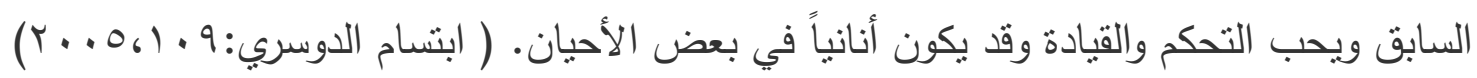
خصائص النمو الجسدي : تزداد سرعة النمو الجسمي في هذا العمر وتزداد قابلية الطفل للمرض. يزداد تمركز الطفل حول نفسه (الأنانية). تختلف سرعة النمو بين الأطفال الذكور والإناث حيث تكون أسرع عند الإناث. يتأخر نمو العضلات قليلاً وتزداد الحركة واللعب والنشاط بشكلٍ ملحوظٍ. ثبقى عظام الرأس لينةً

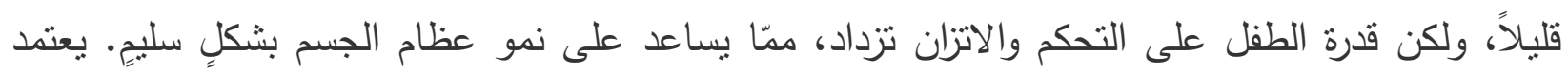

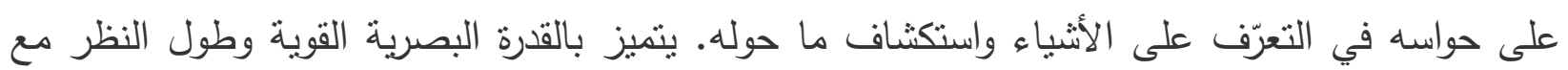
رؤية الأشياء ذات الحجم الكبير بشكلٍ أوضح من الأثياء الصغيرة. يستخدم اليدين بشكلٍ كبيرٍ وبكفاءةٍ

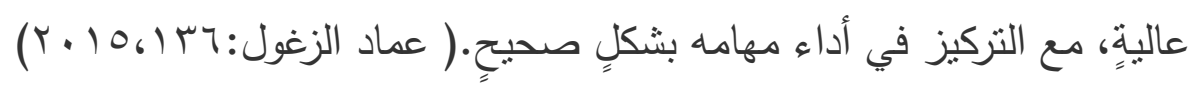

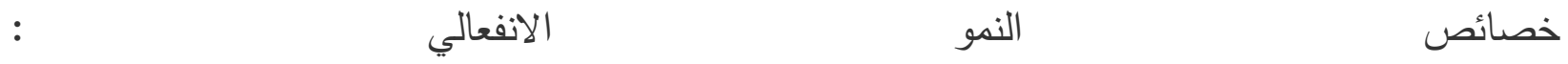
تزداد حدة انفعالاته وقوتها، ويكون كثثر التقلب في ردود أفعاله وانفعالاته. يميز الأدوار التي يقوم بها أفراد

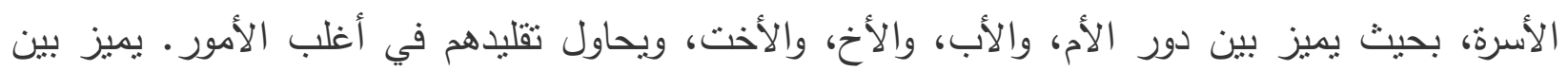
التصرفات المقبولة اجتماعياً وبين التصرفات غير المقبولة، ويكون هذا التمبيز تدريجياً وليس مرةً واحدةً وهذا يتوقف على الطريقة التي يعامله بها أهله. يحبّ السيطرة بشكلٍ أكبر من السابق ويحب التحكم والقيادة

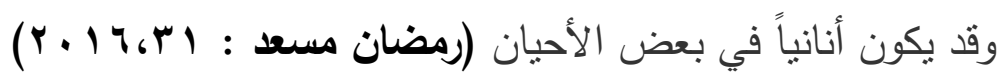

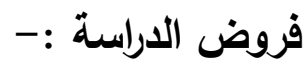
- توجد فروق ذات دلالة إحصائية بين متوسطات درجات القياسين القبلي والبعدي للطالبات1 
المعلمات عينة الدراسة على الاختبار التحصيلي في محور الوسائط التعليمية لصالح القياس البعدي بعد تطبيق البرنامج

- توجد فروق ذات دلالة إحصائية بين متوسطات درجات القياسين القبلي والبعدي للطالبات بـات المعلمات عينة الدراسة على الاختبار التحصيلي في محور جوانب نمو طفل الروضة لصالح القياس البعدي بعد تطبيق البرنامج

- توجد فروق ذات دلالة إحصائية بين منوسطات درجات القياسين القبلي والبعدي للطالبات3

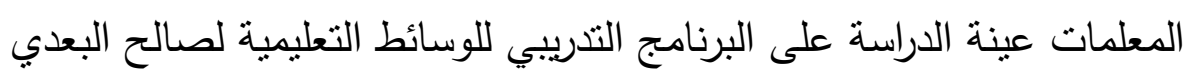

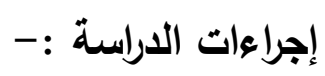

\section{تفسير نتيجة الفرض الأول}

توجد فروق ذات دلالة إحصائية بين متوسط درجات الطالبات المعلمات في التطبيق القبلي ومتوسط درجات نفس المجموعة على التطبيق البعدي على الاختبار التحصيلي للطالبات المعلمات على الوسائط التعليمية وجوانب النمو لصالح الاختبار البعدي.

تم حساب المتوسطات والانحرافات المعيارية وقيم (ت) بين متوسطي درجات الطالبات المعلمات على التطبيق القبلي ودرجاتهم على التطبيق البعدي على الاختبار التحصيلي للطالبات المعلمات في انتاج الوسائط التعليمية لتمية جوانب النمو لاى اطفال الروضة بالتدريب الميداني كما يتضح فى الجدول التالي: 


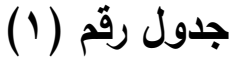

نتائج اختبار (ت) لدلالة الفروق بين درجات الاختبار التحصيلى للمجموعة التجريبية قبل ويعد تطبيق البرنامج

\begin{tabular}{|c|c|c|c|c|c|c|c|}
\hline الدلالة & الفروق دلالة & الحرية & قيمة ت & الانحراف & المتوسط & عدد & المجموعات \\
\hline \multirow[t]{2}{*}{$\cdots+1$} & \multirow[t]{2}{*}{ دالة **\% } & \multirow[t]{2}{*}{$r q$} & \multirow[t]{2}{*}{$r 0 . r \leqslant r$} & ᄉ. $\varepsilon .9$ & $14.9 \ldots$ & $r$. & القبلى \\
\hline & & & & $\because V Y \leq$ & $T V . \varepsilon \ldots$ & $r$. & البعدى القياس \\
\hline
\end{tabular}

يتضح من الجدول السابق أن قيمة (ت) تساوى سع ب.0 وهي قيمة دالة عند مستوى ( ..... وهذا يدل على وجود فروق بين متوسط درجات الاختبار القبلي ومتوسط درجات الاختبار البعدي على الاختبار التحصيلي للطالبات المعلمات في توظيف الوسائط التعليمية لتتمية جوانب النمو لاى الأطفال ، وذلك نتيجة استخدامهم برنامج لتدريب للطالبة المعلمة قائم على انتاج الوسائط التعليمية لتتمية جوانب النمو لطفل الروضة، وبالتالي نم قبول الفرض البديل والذى ينص على أنه "توجد فروق ذات دلالة إحصائية بين منوسط درجات الطالبات المعلمات فى التطبيق القبلى ومتوسط درجات نفس المجموعة على التطبيق البعدى على الاختبار التحصيلى للطالبات المعلمات لانتاج وتوظيف الوسائط التعليمية لتتمية جوانب النمو للطفل لصالح

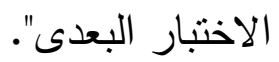


ولتحديد مدى فاعلية برنامج لتدريب الطالبة المعلمة قائم على انتاج الوسائط التعليمية لتتمية جوانب

النمو لطفل الروضة، قامت الباحثة بالمعالجة الإحصائية لنتائج تطبيق الاختبار التحصيلي قبلياً وبعدياً للمجموعة التجريبية، وتم حساب الفاعلية باستخدام معادلة بلالك Black للكسب المعدل.

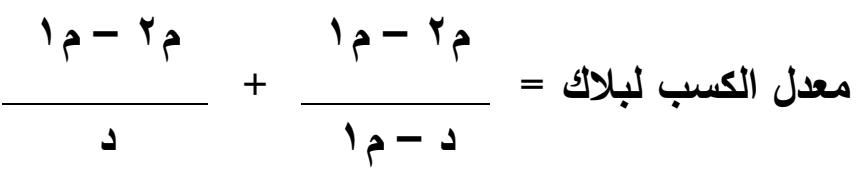

حيث بدل مץ-م // د - م ا على فاعلية البرنامج في التطبيق القبلي والبعدي"('.ويتضح ذلك في الجدول التالي:

\section{جدول (r)}

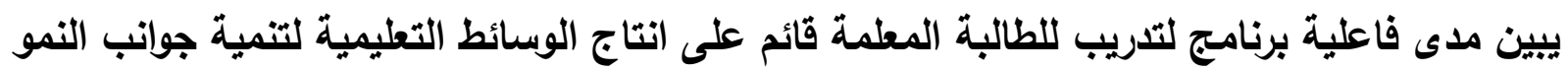
لطقل الروضة لاى مفردات المجموعة التجريبية بمقارنة التطبيقين القبلي والبعدي للاختبار المبار

\begin{tabular}{|c|c|c|c|}
\hline نسبة الكسب المعلد & الفاعلية & متوسط درجات التطبيق & متوسط درجات التطبيق \\
\hline 1.21 & .90 & TV.乏.. & $15.9 \ldots$ \\
\hline
\end{tabular}

يتضح من الجدول السابق أن برنامج تدريب الطالبات المعلمات على انتاج الوسائط التعليمية يتصف

بالفاعلية فى تتمية جوانب النمو للأطفال لدى مفردات المجموعة التجريبية بمقارنة النطبيقين القبلي والبعدي للاختبار ، حيث بلغت الفاعلية 90. .، وهى قيمة قريبة من الواحد الصحيح، مما بدل على أن البرنامج له فاعلية عالية فى تتمية مهارات الطالبة المعلمة، كما تتضح كذلك فاعلية (برنامج تدريب الطالبة المعلمة القائم على انتاج الوسائط التعليمية لتتمية جوانب النمو لطفل الروضة) لدى مفردات المجموعة التجريبية من خلد قيم الكسب المعدل للطالبات المعلمات في النطبيق البعدي حيث بلغت اV.1. وتلك القيمة > r, أوهو المدى الذى حدده بلالك لفعالية البرامج التنريبية . - الم 
ويتضح من الجدول السابق فروق المتوسطين لارجات المجموعة التجريبية في النطبيق القبلي والنطبيق البعدي على الاختبار التحصيلي، ونسبة الكسب المعدل ( I I ( ) تكثف عن فعالية البرنامج المستخدم في تتمية جوانب النمو للأطفال لدى مفردات المجموعة التجريبية، وبالتالي تمت الإجابة عن سؤال الدراسـة ، حول فاعلية برنامج لتدريب الطالبة المعلمـة قائم علي انتاج الوسـائط التعليمية لتتمية جوانب النمو لطفل ال - ماروضة.

\section{تفسير نتيجة الفرض الثانى:}

الذي نص على وجود فروق دالة إحصائياً بين منوسطات رتب درجات الطالبات المعلمات على الاختبار التحصيلي للطالبات المعلمات في القياسين القبلي والبعدي لصالح القياس البعدي.

وترجع الباحثتان هذه النتيجة إلى حدوث نمو ملحوظ في المعلومات التي اكتسبنها الطالبات المعلمات عن أنواع الوسائط التعليمية - ومراحل انتاجها - كيفية إعدادها وتتفيذها في الروضة وتساؤلاتهن قبل البرنامج عن كيفية تطبيقها واستخدامها في الروضة مع الاطفال وعن تفسير جوانب النمو وخصائصها وكيفية التعرف عليها ومدى أهميتها.

وهذا يتقق مع نتائج دراسة (Fowler - Jean 2000) ودراسة (Bagley-Norman 2000) ودراسة (Arizona State Dep. 2001) وربطها بورش عمل للأطفال واستخدام أفكار جديدة إبداعية لتتمية جوانب النمو عند الأطفال وأهمية تطوير أساليب التعلم في الروضة.

وترى الباحثتان أن استخدام الاختبار التحصيلي أفاد الطالبات المعلمات في إثارة دافعيتهم نحو البرنامج التدريبي من خلال المعلومات التي حصلن عليها بعد تطبيق البرنامج فقد أثار انتباههن بعض المصطلحات التي وجدنها غامضة عند التطبيق القبلي وأصبحت أكثر سهولة ومتاحة بعد التطبيق البعدي ولقد اتضح لهن أن البرنامج التنريبي يتصف بالحداثة والجدية والمعلومات القيمة. 
- كذللك دفعن إلى طرح الأسئلة المعدة مسبقاً أثناء البرنامج التدريبي وتفاعلهن مع الباحثتان بحماس. - - أيضاً لفت أنظار الطالبات المعلمات إلى ضرورة الاطلاع دائهاً على كل ما هو جديد في مجال عمهن من أساليب جديدة لتعلم طفل الروضة، ابتكار أنشطة جديدة لتتمية جوانب النمو للأطفال، واستخدام الوسائط التكنولوجية المختلفة وتوسيع نطاق تقديم الأنشطة داخل وخارج قاعات الروضة، وإطلاق الحرية للأطفال لممارسة أنشطة متتوعة وجديدة في الروضة.

وهذا ما أكدت عليه (Erin Ricsland 2009) بقولها لابد من مشاركة جميع الأطفال في أنشطة مبتكرة والاستفادة منها في حياتهم اليومية.

وتخلص الباحثنان مما سبق إلى تحقق صحة الفرض الثالث في وجود فروق دالة إحصائياً بين متوسط درجات الطالبات المعلمات في النطبيق القبلي ومنوسط درجات نفس المجموعة في النطبيق البعدي على الاختبار التحصيلي للطالبات المعلمات على الوسائط التعليمية وجوانب النمو لصالح الاختبار البعدي.

\section{تفسير نتيجة الفرض الثالث}

تحديد مدى فاعلية البرنامج التدريبي للطالبات المعلمات على الوسائط التعليمية وأثرها على تنمية جوانب

النمو المختلفة :

$$
\text { قبل تطبيق البرنامج أنثارت الطالبات المعلمات إلى ما يلي: }
$$

- عدم إلمامهن بطرق انتاج الوسائط التعليمية للأطفال في الروضة ومنها القصة حيث أن ساعة القصة من أهم الأنشطة التي تقدم في الروضة ولكن من ملاحظتهن أثناء المشاهدات الميدانية أن معلمة الروضة لا يقدمن للأطفال إلا رواية القصة بطرق تقليدية - عدم معرفتهن بأنواع الوسائط التعليمية وطرق إنتاجها واستخدامها في الروضة حيث أنهن يستخدمن أنواع بسيطة الصنع ورقية ويعثقدن أنه لا نوجد أنواع أخرى من الوسائط التعليمية منل الكتيب المصور

$$
\text { الملون يمكن تقديمه في الروضة. }
$$


- الاقتصار على تقديم الأنشطة الأخرى التقليدية من منل أفلام كارتون في خلال البرنامج اليومي وبعض الأعمال الفنية البسيطة

- - عدم استخدام وسائط إلكترونية أو تتقيفية لمساعدة الأطفال على تتمية جوانب النمو المختلفة وبعد تطبيق البرنامج أثشارت الطالبات المعلمات إلى ما يلى:

- زيادة معرفته بأساليب رواية القصة وطرق تقديمها للأطفال بطريقة مشوقة وجذابة. - كثرة الإلمام بأنواع الوسائط التعليمية وخاصة القصص المتتوعة واستراتيجيات تقديمها و ومراحلها وطريقة إعدادها حيث أنهم قاموا بنطبيقها أثناء البرنامج التدريبي - الاتفاق علي انه لابد من تقديم روئة جديدة للأنشطة المقدمة في الروضة تمكن المعلمة من معرفة خصائص نمو الأطفال لتنميتها .

- - مرورة استخدام بعض الوسائط والوسائل أثناء تقديم الأنشطة وتتمية جوانب النمو في الروضة. - ومما يؤكد فعالية البرنامج التدريبي أيضاً طلب الطالبات المعلمات بضرورة عقد لقاءات تدريبية مستمرة لتتميتهم مهنياً واطلاعهم على كل ما هو جديد في مجال رياض الأطفال وهذا ما اتفق مع (دراسة خالد حسين (1) من ضرورة تقدير الاحتياجات التدريبية للطالبات المعلمات بصفة مستمرة للوقوف على

$$
\text { جوانب القوة والضعف وتتميتها. }
$$

ومن خلال الدراسة الحالية تحققت صيغ فروض البحث وكانت النتائج كالآتي:

1- نوجد فروق ذات دلالة إحصـائية بين منوسطي درجات أفراد المجموعة التجريبية في القياسين القبلي والبعدي في انتاج الوسائط التعليمية لصالح القياس البعدي. r- لا توجد فروق ذات دلالة إحصائية بين متوسطي درجات أفراد المجموعة التجريبية في القياسين البعدي و التبعي في تطبيق الوسائط التعليمية.

r- توجد فروق ذات دلالة إحصائية بين متوسطي درجات أفراد المجموعة التجريبية في القياس البعدي في تطبيق الوسائط التعليمية. 
في ضوء أهداف الدراسة وفروضها، وفي حدود طبيعة المنهج والعينة والمعالجات الإحصائية المستخدمة ومن خلال نتائج الدراسة ومناقشتها، توصلت الباحثتان إلى مجموعة من الاستخلاصات التالية: ا - استخدام برنامج لتدريب الطالبة المعلمة على انتاج الوسائط التعليمية وتتمية جوانب النمو كان له أثر كبير في تتمية مهاراتها لاستخدام الوسائط التعليمية وعمل تطبيقات وأنشطة متتوعة في الروضة أثناء

$$
\text { المشاهدات الميدانية. }
$$

ץ- استخدام التدريبات المنتوعة والتدرج في الخبرات المقدمة لعينة الدراسة لهما دور فعال في تتمية المهارات

لاى الطالبات المعلمات بشكل كبير ·

r- استخدام التعزيز المستمر وإعطاء الفرصة للنقد والتقييم كان له أثز فعال في نجاح البرنامج التدريبي. ع - تقدم مستوى الطالبات المعلمات في القياسين البعدي والتتبعي في تحسين مهاراتهن في انتاج الوسائط التعليمية وكيفية توظيفها في الروضات يدل على فاعلية البرنامج التدريبي المستخدم في الدراسة. 0- الابتعـاد عن الطريقة التقليديـة في إعطاء المحاضـرات واستخدام وسـائط تعليمية مثل عروض الفيديو PowerPoint

عينة الدراسة

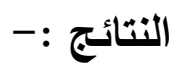

توصلت الباحثتان إلى مجموعة من النتائج وهى 1 -توجد فروق ذات دلالة إحصائية بين متوسطات درجات القياسين القبلي والبعدي للطالبات

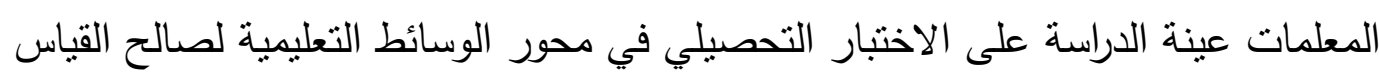
البعدي بعد تطبيق البرنامج

2- نوجد فروق ذات دلالة إحصائية بين منوسطات درجات القياسين القبلي والبعدي للطالبات

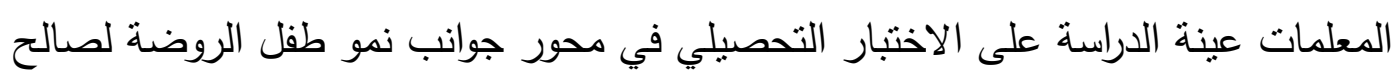
القياس البعدي بعد تطبيق البرنامج 
3 -توجد فروق ذات دلالة إحصائية بين متوسطات درجات القياسين القبلي والبعدي للطالبات المعلمات عينة الدراسة على البرنامج التدريبي للوسائط التعليمية لصالح البعدي لئي توصبات الدراسة: في ضوء نتائج الدراسة نوصي الباحثتان بما يلي:-

نشر الوعي لاى الطالبات المعلمات نحو أهمية استخدام أنشطة واستراتيجيات جديدة في رياض الأطفال. • الاهتمام بالتدريب الطالبات المعلمات وتقديم الخبرات الأجنيية لمعرفة المستجدات على أرض الواقع. • ضرورة متابعة تقدم الأطفال في الانثطة المتتوعة لاكتثاف الموهوبين منهم وتتميتهم.

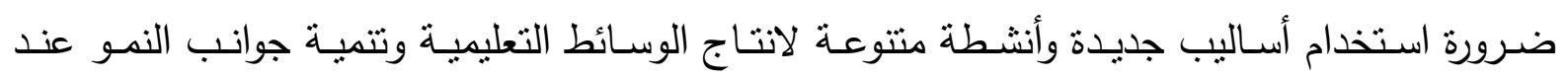
الأطفال التأكيد على المام الطالبة في كيفية توظيف الوسائط بالمواقف التعليمة بشكل مناسب للعملية التعليمية وللمرحلة العمرية. هلابد من مراعاة عمر الطفل انتاج الوسائط التعليمية لتمية جوانب نمو الطفل المختلفة.

1. ابتهاج محمود طلبة برامج طفل ما قبل المدرسة، القاهرة ، حورس للطباعة والنشر، ، . ؟ . r. ابتسام الدوسري : الأساليب والوسائل التعليمية وبناء المنهج في رياض الأطفال ،المملكة العربية

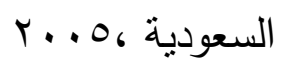
r. إبراهيم محمد عبد الرحمن عرمان : أثز استخدام الوسائط المتعددة التفاعلية القائمة علي الحاسوب على تحصيل طلبة الدراسات العليا في مقرر استخدام الحاسوب في التربية ،مجلة جامعة القس

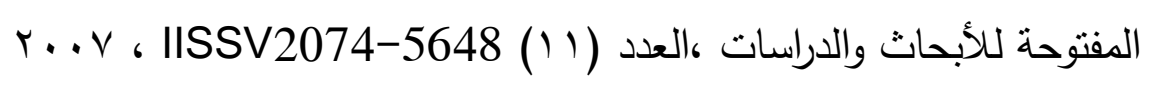
ع. أحمد مصطفى عصر ،إيهاب مصطفى جادو : فاعلية الوسائط المتعددة في اكساب معلمات رياض الأطفال مهارات تصميم وإنتاج البرمجية التعليمية لطفل الروضة ،معهد الدراسات التربوية ، جامعة

$$
\text { القاهرة ، 1 . . ب }
$$


هـ أحمد حسين اللقاني، على أحمد الجمل: معجم المصطلحات التربوية المعرفة في المناهج وطرق

$$
\text { التدريس، عالم الكتب، ص.999 }
$$

7 ـ الإدارة العامة للتربية والتعليم: التدريب أثناء الخدمة، منطقة القصيم.

$$
\text { r.. } 9 \text { http://www.aasimedu.gov.sa }
$$

V. إيدينجتون، مارجريت: (ترجمة خالد العامري) معلمة رياض الأطفال، دار الفاروق للاستثارات

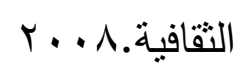

A. أمجد عمر صفوري :تصميم وإنتاج واعداد الوسائط المتعددة، كلية الصحافة والاعلام ،جامعة

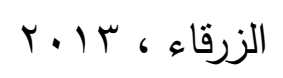

9. جودت عزت عبد الهادي: الإشراف التربوي (مفاهيمه وأساليبه، دليل لتحسين التدريس)، عمان، دار

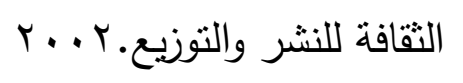

• 1. عن شحاتة، زبنب النجار : معجم المصطلحات التربوية والنفسية،القاهرة ، الدار المصرية

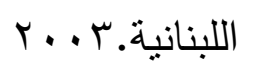

ا ا. حسن أحمد الطعاني : التدريب مفهومه وفعالياته في بناء البرامج التدريبية وتقويمها ، دار

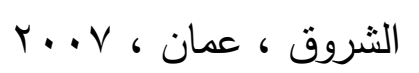

ץ ا. الد حسين إبراهيم: تقدير الاحتياجات التدريبية لأمناء المكتبات العامة المصرية، دراسة تحليلية للطرق التقليدية وإمكانيات تطبيق طرق حديثة، كلية الآداب، جامعة حلوان. . . . F

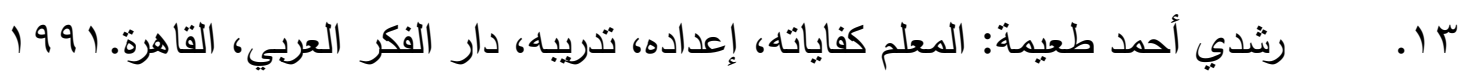
مضان مسعد بدوي : تتمية المفاهيم والمهارات الرياضية لأطفال ما قبل المدرسة ، دار الفكر العربي

$$
\text { r. } 17 \text { ( }
$$

ع ا. عتاب مصطفى: أثز إعداد وتدريب معلمة رياض الأطفال على نجاحها في عملها ، مرصد

$$
\text { نساء سورية (www.nesasy.org). }
$$


10. عاطف محمود عبد العال ،محمد السيد النجار : فاعلية برنامج ألعاب تعليمية إلكترونية في تتمية مهارات استخدام الكمبيوتر لأطفال مرحلة الرياض ، مجلة العلوم التربوية ، العدد الثالث ،

$r \cdot 1 \leq$

17 فعالية تدريس انتاج الصور التعليمية ، مجلة كلية المعلمين ،العدد الرابع المجلد الثاني ، بيشة

$$
\text { r... ¿。 }
$$

V V . عماد الزغول ، علي فالح هنداوي: مدخل الي علم النفس ، دار الكتاب الجامعى ،الامارات

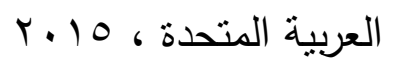

11. على جودة محمد عبد الوهاب: معوقات استخدام معلمي التاريخ للوسائط التكنولوجية المتعددة واتجاهاتهم نحوها ، رسالة دكتوراة غير منشورة ، جامعة بنها ، م ـ . ب.

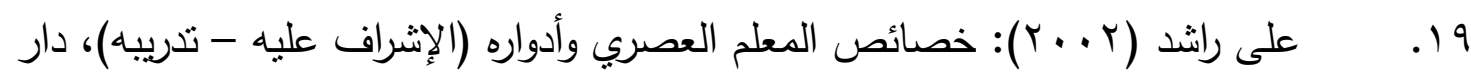

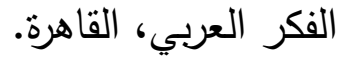

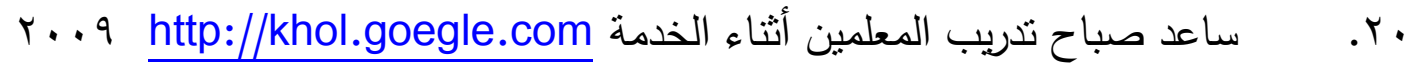
ا.r. سحر توفيق نسيم : تتمية المفاهيم الرياضية لدي طفل ماقبل المدرسة ،مكتبة الرشد ،

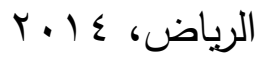

r r. فاطمة عبد الله سلطان الحارثي : فاعلية استخدام الوسائط المتعددة في تعليم المسئولية

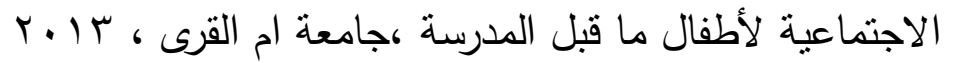

rrr. مجدي عبد الكريم حبيب: دراسات حديثة في تتمية مهارات صنع القرار، مجلة علم النفس، الهيئة المصرية العامة للكتاب، أكتوبر - نوفمبر - ديسمبر ، 11 ب r

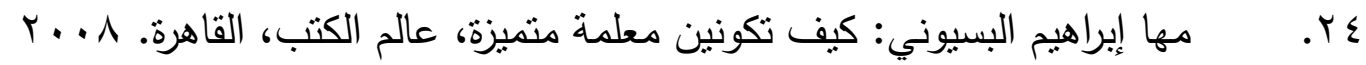
Or. محمد أحمد سعفان، سعيد طه محمود المعلم إعداده ومكانته وأدواره، دار الكتاب الحديث. 
جr. محمد السبد البدوي الدسوقي: كيف تكون مدرباً ومحاضراً مؤثراً ومتميزاً، مركز الإسكندرية

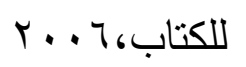

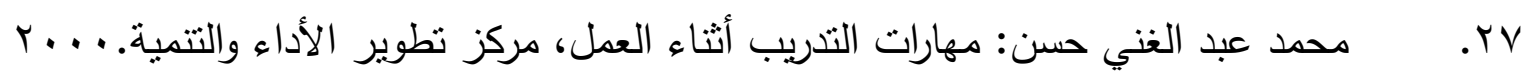

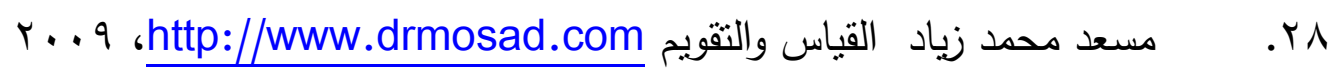

و ب. وفاء عبد الرازق عباس العنبكي :مظاهر النمو في مرحلة الطفولة ،كلية التربية الأساسية ،

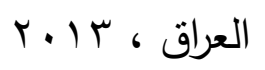

• r. باسمين أحمد محمد : برنامج تدريبي لإكساب الطالبة المعلمة بكليه رياض الاطفال مهارات توظيف القصة فى تتمية ثقافة التغذية الوقائية لطفل الروضة ، رسالة ماجستير غير منشورة ،جامعة

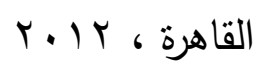

\section{ثانياً: المراجع الأجنبية:}

31--Amanda, Miler: Fall Day in Kindergarten, Eric Clearnig House Elementary and Early Childhood Education, 2004

2-Angeles, Cerezo, M: Emotional and Congitive Adjustment in Abused, rChild Abuse \& Neglect, Vol. (18), Issue, 2003

-Arthur Morvic: The Nature of History, Macmillan Press, London, rr1999-

Barbosa, A: John Dewey andart education in Brazil, Saopaulo, Brazil, $r \varepsilon-2001$

35 - Barton, Keith, Levestik, Linda: Back when god was around and Everything :Kindergarten Children's Understanding of Historcial Time, British .Journal of Psychology, 2009 6 - Carter, James, R: Dora the Explore: Preschool Geographic Educator, rJoural of Geography, Vol.(7), N.(3), 2008 
37 - Dardanou, Maria: And why should I go to the Museum? The

Museum As Alearning Arena for the Kindergarten: Examples from Norway, .University of Tromso, Norway, 2011

38 - Dardanou, Maria: and why should I go to the museum? The museum as Alearning Arena for the Kindergarten: Examples from Norway,

.MA thesis, University of Tromso, Norway, 2011

9- Frostick, Elizabeth \& Kaikamagh, Gaynor, Making City Histories in

־Museum Leiceter University Press, 1998

40 -Hemming, Christopher: Young Children Concepts in History

Developing Concepts in Relation to Citizenship Teaching, Vol. (8), No. (2), .2011

41 -Heyking Amyvon: Histrocial Thinking Program in the Early Years, .American Educational Research, Journal, Vol. (29), No. (4), 2012

42 -Hinde, Elizabeth and Others: The integration of Literacy and Geography: The Arizona Geoliteracy Program's Effect on Readnig Comprehension, Theory and Research in Social Education Vol.(35), No.(3), .2010

43 -Holmes Julie, A: Use of Pre-and post Museum Visit Classroom Activities by Kindergarten Children in Developing some patrotism Values, Literacy information and computer Education Journal, Special Issue, Vol. (1), .No. (1),2012

44 -Krechevsky, Mseide, S: Minds Atwort Applying Multiple in Telligences in the Classroom in insternberg, 1998 
45 -Kubiatko Milan and Others: Gender and Grade Lvel as Factors in Fluencing Perception of Geography, Review of International Geographical .Education, Online, Vol.(2), No.(12), 2013

6 -Maxim, Geogre: Developmentally Apropriate Map Skills Instruction, 乏Childhood Education, Vol. (73), No. (4), 1997

47 -Mosterman, Elizabeth: A frame work for designing interactive multimedia to scaffold young children's under standing of historical .choronology, instructional since, vol. (30), No. (3), 2002 48 -Nelson, Lynnr, Nelson Trudya: Learning history through childrens .Literature, Eric Cleaing House for Social Studies, 2000 49 -Quintero, Iliana: Understanding Childern's Conceptions Geographical Space, Harvard University, 1999 50 -Ralph C.preston and Herman Wayne: Teaching of Social Studies in .Elementary School, New York, Hotrinehart and Wenston, 1999 51 -Smith, Brain, Reiser, Brain: National Geographic Unplugged:

Classroom - Centered design of interactive Nature fimls, proceeding of Chi, .ACM press, New York, 2012 52 -Tortello, Ramecca Morie: Children get your culure: Jamaican Children and Their Museum Experiences in Formal Education and the Development of Indivdualism, Dissertation Abstract, Vol. (63), No. (4), .Section A, 2002 53 -Walker, Scott, L: Early Instruction in Geography: An Exploration in the Ecology of Kindergarten and First-Grade Geography Education, Journal of .Geography, Vol. (106), No. (3), 2007 
4 -Hope,Warren C.: It,s Time To Transform Social Studies Teaching: Social •Studies:V.87, N.4, Jul-Aug, 1996, pp.149-151

-White, Charless. : Multimedia Products For U.S.History : Social Education, 55.V.60, N.6, Oct. 1996, pp. 379-83

-Wheeler, Ron: R X For Scial Studies : Social Education, V.60 N.5, Sep, ○ 07.1996,pp 313-

-Benedicks, William, Jr; Felton, Randall G. : AN Interactive .Multimedia 57.Review, Social Studies ; V.85,N.4,1994,PP185-86

58-Martorella, Peter H.:Harnessing New Technologies To The Social Studies

Curriculum; Social Education ; N.1, Jan,1991, PP. 55-57 V.55

59-Fernlund, Phyllis Maxey;A Realistic View Of Hypermedia In The Social Studies Classroom, Social Studies Review; V.30 N.3,Spr., 1991 PP 66-70 60-Crane, Beverly: Information Technology: Stepping Stone To The Future, Social Studies Review;V. 32, N.2, 1993, PP. 44-49

-Cohen, Kathleen; Can Multimedia Help Social Studies, Or Are

$7)$ Videodiscs Worth The Expense

.Social Studies Review;V. 32, N.2, 1993, PP 35

62 -Butler, Judy D. , Clouse, R. Wilburn: Educational Technology and The Microfiche, Teaching of History : Promise,Practice and possibilities:Paper May,1994, 29 pages

63 -Peeples, Lucretia: Validating Students: A Collaborative Model: Elementary .School Review: Social Studies Review: V. 34, N. 3, Spr.1996, pp 44-49 Milah Micheal \& Dianna vllus (1998): Designing powerful training feiffer, $7 \varepsilon-U S A$ 